\title{
POSSIBLE ACCUMULATION AND RECIRCULATION OF POLLUTANTS IN THE ATMOSPHERE OF THE HIGHVELD
}

\author{
G Held, H Scheifinger and G M Snyman \\ Environmental Sciences, Eskom, Technology Research and Invesgitations \\ Private Bag X40175, Cleveland 2022
}

\begin{abstract}
SYNOPSIS
Particulate concentrations were monitored by the CSIR during a five-year period at 23 sites on the Highveld. However, not all sites were operating concurrently or for equally long periods. Stacked filters $(8$ and $0,4 \mu \mathrm{m})$ were exposed for 24 hours and then analysed for five particulate species (sulphate, nitrate, chloride, phosphate and fluoride).

More than 150 case studies have been selected from the five-year database. Synoptic features of the atmospheric circulation over the southern African subcontinent could successfully be linked with the sulphate behaviour on the Highveld and summarised by a few classes of characteristic synoptic situations. Westerly ventilation, easterly ventilation and washout events were identified to reduce the sulphate level on the Highveld on an average of 17 times per year. On the other hand, a simple assessment showed that stagnating conditions can dominate during any period of the year because the total sulphate mass, observed during regularly occurring episodes, would need an accumulation period in the range of 10 to 20 days. This finding relates well to the subtropical anticyclonic belt influeincing the pattern over the Highveld during the whole year.

Meteorological evidence was found for the existence of various mechanisms which ultimately could lead to an accumulation or recirculation of pollutants on the South African Highveld (approximately 19 occurrences per year). Although relatively high episodes of particulates, especially sulphate and nitrate, were occasionally observed at elevated sites (approximately $300 \mathrm{~m}$ above the surrounding terrain), it must be emphasized that ground-level concentrations on the Highveld are, in general, low (sulphate rarely exceeded the California limit of $25 \mu \mathrm{g} \cdot \mathrm{m}^{-3} / 24 \mathrm{~h}$ ). However, there are still a number of unanswered questions which need to be resolved before final conclusions can be drawn.
\end{abstract}

\section{INTRODUCTION}

The behaviour of the particulates on the South African Highveld appears to differ in many respects from what is known about particulates in the northern hemisphere. The unique combination of industrial settlements on the plateau of the southern Africa continent, with its subtropical climate, may account for the phenomena solely recorded there.

Over the past few years, the CSIR's Division for Earth, Marine and Atmospheric Science and Technology (Ematek) has observed significantly higher than usual episodes of secondary pollutants at sites situated above the "standard" $3 \mathrm{~m}$ above ground level (AGL). This phenomenon has been observed simultaneously at sites such as Verkykkop (Volksrust) and on top of the stack at Kendal Power Station, both of which are some 270 to 300 $\mathrm{m}$ above the surrounding terrain ${ }^{1}$.

At ground-level (air intake $3 \mathrm{~m} \mathrm{AGL),} \mathrm{the} \mathrm{daily} \mathrm{values} \mathrm{for}$ sulphate vary from 1 to $15 \mu \mathrm{g} \cdot \mathrm{m}^{-3}$ with a monthly average of $4 \mu \mathrm{g} \cdot \mathrm{m}^{-3} .^{2}$ On top of Verkykkop it has been found that averages are about twice as high, viz. in the region of $8 \mu \mathrm{g} \cdot \mathrm{m}^{-3}$, with daily values of up to $64 \mu \mathrm{g} \cdot \mathrm{m}^{-3}$ having been measured ${ }^{3}$.

At present, in South Africa, there is no standard or guideline for acceptable levels of any of the secondary pollutants and, as far as can be ascertained, the only prescribed maximum for sulphate is that of the California Air Quality Board measured at ground level. The level of $25 \mu \mathrm{g} \cdot \mathrm{m}^{-3} / 24 \mathrm{~h}$ has been laid down by them. However, it should be noted that even levels referred to in this paper as "severe" do not exceed this limit.

Vertical profiles, of mostly secondary pollutants, were obtained by Ematek by means of a radio controlled model aircraft. ${ }^{4}$ It was shown that up to a height of about $800 \mathrm{~m}$ (the ceiling height of the model aircraft) the pollutants can either increase in concentration or be concentrated in layers. The ratio of nitrate to sulphate was found to be closer to 1:1 or less at higher elevations, whilst at ground level the ratio was usually 1:3 or higher. The same phenomenon was observed at both Verkykkop and Kendal.

As yet, there is little or no knowledge of the concentration levels of particulate pollutants in the forestry areas of the Eastern Transvaal, or of the influence that the pollution emanating from the PWV-ETH industrial/residential area has on pollution levels outside this area. Thus, it would be of value not only to Eskom and certain government departments, but also to the public in general, to be able to prove or disprove the postulated accumulation of pollutants at higher elevations. Therefore, Eskom commissioned Ematek to summarise the current knowledge on particulates. 5 . This paper is an extract of the aforementioned report pertaining only to case studies and the possible link between certain synoptic situations and particulate concentrations over the Highveld.

\section{SAMPLING SITES AND METHODS}

During 1982, a sampling network for particulates was set up in the Eastern Transvaal Highveld (ETH) area. The original network consisted of nine sites each equipped with a unit comprising a pump, a gas meter, an eightposition rotary valve which is time-activated and a canopy housing eight filter holders at a height of $3 \mathrm{~m}$ AGL. These stacked filter holders ( 8 and $0,4 \mu \mathrm{m}$ filters) are coupled to the ports on the rotary valve which changes position every 24 hours (midnight) so that a different filter set is exposed each day. However, only the total air volume, from which daily average values are calculated, could be recorded when the site was visited once a week. Episodes of very high particulate levels obviously can cause filter blockage and thus result in lower air flow rates which cause peaks 
to be underestimated and concentration minima to be over-estimated ${ }^{2}$.

All filters were analysed by ion chromatography and the quantity of fluorides, chlorides, phosphates, nitrates and sulphates on each filter was then determined $\left(\mu \mathrm{g} \cdot \mathrm{m}^{-3} / 24\right.$ h).

During this investigation, certain sites were abandoned and others chosen, which means that some sites were used for seven years and others for two years, depending on their positions (Figure 1). At any one stage up to 15 samplers were deployed simultaneously within the network. Initially, the sites were all close together, many of them co-located with anemometers and close to the area with the highest concentration of power stations. However, because of the high stacks at the power stations, it was later felt that the deposition of the aerosols was actually taking place further afield. This led to spreading of the network. In June 1985, a sampler was erected on a hill (Verkykkop) outside Volksrust (Figure 1) which is approximately $150 \mathrm{~km}$ southeast and thus downwind of the major source area when the predominantly northwesterly winds blow. The hill has steep precipitous sides rising to an elevation of about $300 \mathrm{~m}$ above the surrounding area. After maximum sulphate concentrations up to six times higher than those at ground level were measured, a sampler was also installed in Volksrust (at the foot of the hill) for comparison purposes. The sampling point on top of Verkykkop is regarded as sampling in the free atmosphere some $300 \mathrm{~m} \mathrm{AGL}$ and not as being representative of ground-level concentrations. Another elevated site could be maintained for 15 months on top of Kendal power station stack (about 270 m AGL).

\section{THE RELATIONSHIP BETWEEN SYNOPTIC SITUATIONS AND GROUND-LEVEL CONCENTRATIONS OF SULPHATE}

Based on a wealth of case studies of the sulphate behaviour at the surface ${ }^{6}$ an attempt was made to establish some general relationships between the various synoptic situations and sulphate concentrations. The most significant individual sulphate variations were interpreted, taking into consideration the atmospheric conditions from which the following classification of weather patterns was derived: easterly ventilation (EV), westerly ventilation (WV), washout (WP), tropical cyclone (TC), local conversion and accumulation (LCA), recirculation (RC) and downmixing (DM). Each of the classes will be described shortly and commented on with respect to their impact on the sulphate levels measured on the Highveld.

The classification describes only what appears to be the most prominent meteorological feature. It is quite possible that more than one meteorological phenomenon contributes to the decrease or increase of the $\mathrm{SO}_{4}{ }^{2}$ concentrations at the surface. In the case where a cut-off low is active close to the Highveld or a bud-off anticyclone causes an intense onshore flow, a combination

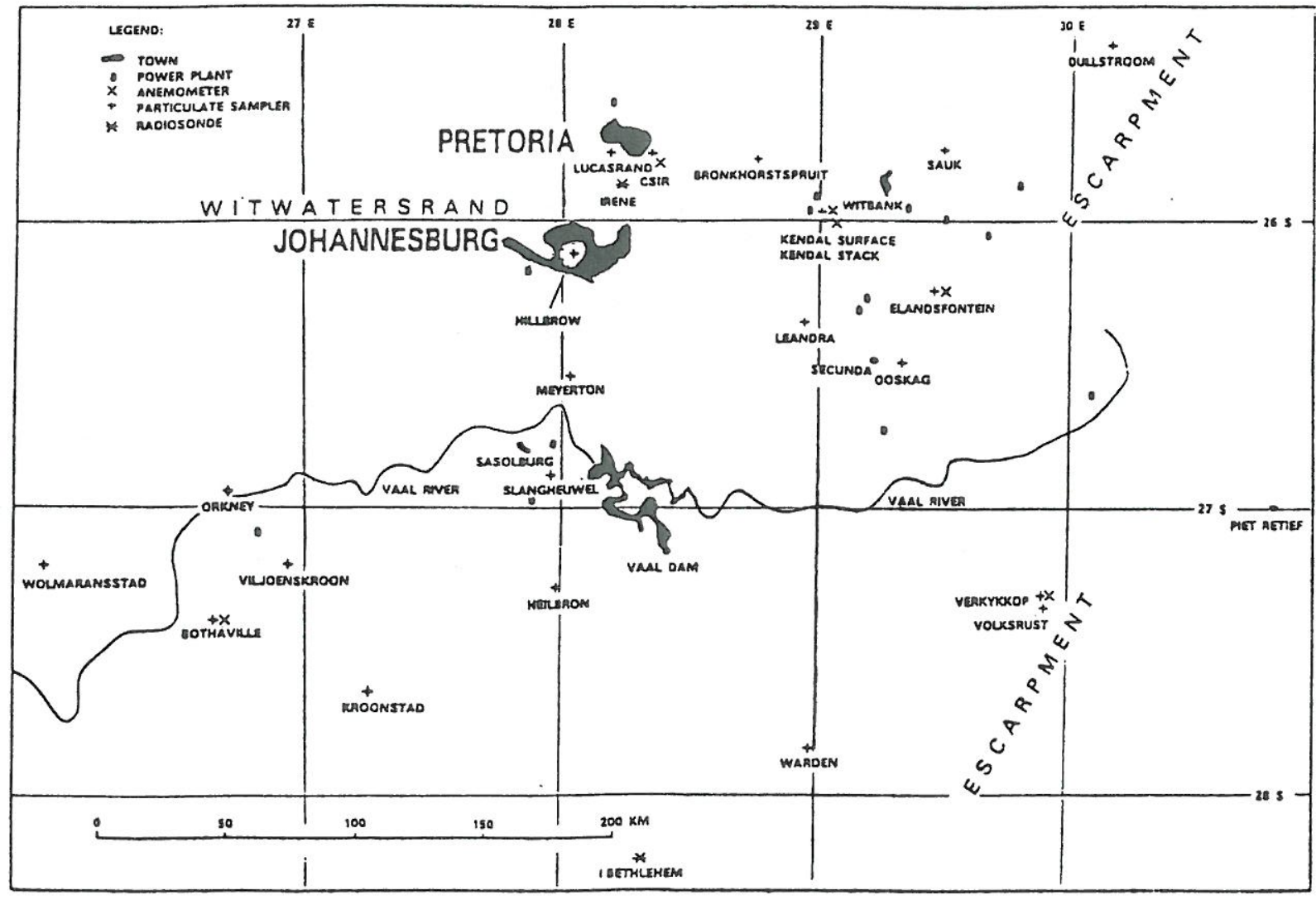

Figure 1. The monitoring network on the South African Highveld depicting particulate sampling sites, anemometers and upper at stations. 
of widespread precipitation and ventilation is likely to reduce the $\mathrm{SO}_{4}^{2-}$ reservoir over the Highveld. On the other hand, the combined effect of LCA, RC and DM could contribute to a rapid increase of $\mathrm{SO}_{4}{ }^{2}$ concentrations at the surface.

The synoptic systems responsible for ventilation of the Highveld, with a westerly air flow (WV), are troughs approaching the subcontinent. The distance of the system from the Highveld, its travelling speed and its intensity vary greatly from case to case, and thus define the ultimate direction of the air flow (northwesterly to southerly) and the degree of ventilation. An air flow from a westerly direction usually results in an advection of a continental type air mass, which is more or less free of pollutants (originating from a non-source area), dry to very dry and warm. Only in the case of rare cold snaps during winter and springtime are modified maritime air masses forced across the subcontinent into the network area. Westerly ventilation occurs most frequently during winter and springtime (May to September), when the westerlies are shifted closest to the subcontinent and baroclinity is high (during springtime).

In the case where a bud-off anticyclone is well developed, it can initiate a strong onshore flow over the eastern parts of the subcontinent. The easterly flow (EV) is well able to ventilate the Highveld and occurs mainly during September to November, when the baroclinity is at its highest. EV occurred 16 times during the time period from May 1985 to November 1988 compared with 37 WV cases. It turns out that only in the case of a well developed sequence of meteorological events does easterly ventilation tend to occur whilst weakly developed sequences are not able to reduce the sulphate levels. In the latter case the sulphate reservoir is rather 'pumped up' every time the source area is crossed by the same air mass.

Infrequently washout events (WO) are responsible for a reduction of the surface $\mathrm{SO}_{4}^{2-}$ levels (eight cases from May 1985 to November 1988). There might have been more occurrences, but if they did not cause a significant drop of the surface $\mathrm{SO}_{4}{ }^{2}$ concentration, they were not taken into account. The synoptic systems involved in the precipitation events were cut-off lows, upper air troughs, summertime, continental lows and, in most cases, intense bud-off anticyclones causing a strong onshore flow of maritime air.

There was only one case, on 24 February 1986, where a tropical cyclone (TC) advected air towards the ETH, thus reducing the $\mathrm{SO}_{4}^{2}$ concentration in the whole network area. The above described ventilation situations occur on an average of 17 times per year.

Over the Highveld, the basic pressure pattern throughout the year is directly linked to the subtropical anticyclonic belt. Conversion and accumulation of pollutants are commonly observed under these conditions. Consequently, a particulate reservoir, intact during most of the time, is the rule, while thorough ventilation only occurs infrequently. The relatively small size of the measurement network ( 500 by $270 \mathrm{~km}$ ) makes it rather difficult to track the air mass movement throughout a complete episode. Inevitably, an air mass with a high sulphate level, which will be referred to as the sulphate reservoir, might leave and again re-enter the network area at a later stage. This was in fact observed as a regular phenomenon occurring all year round (on average 19 times per year). Therefore, local conversion and accumulation (LCA), occurring only within the network area, turned out to be of minor importance because it would require very slow moving air masses within the small network area. Situations which allowed such quasistationary conditions only happened infrequently. The few situations, which could be classified as LCA, occurred mainly during May, when the mean wind speed has its seasonal minimum.

It will be shown that the overwhelming majority of cases with relatively high sulphate levels on the Highveld occurred together with an air mass movement out of and back into the network area. Depending on the season, the sequence of weather patterns characteristic for the southern African subcontinent results in a distinct air mass movement on the Highveld. During all seasons, meteorological events originating in the westerlies will exert an influence on the air flow on the Highveld. In winter, the Highveld lies in the intersecting zone between the westerlies and the subtropical anticyclonic belt. In summer, the influence of events in the westerlies will still penetrate far enough north to change the pressure pattern over the subcontinent. As already stated above, only a well developed sequence of meteorological events possesses the potential to fully ventilate the Highveld as a whole. The majority of disturbances quickly weaken and dissolve while approaching the Highveld.

Another mechanism which needs to be considered for the ventilation of the ETH is the nocturnal Low-Level-Jet (LLJ) which develops during most nights and especially during winter ${ }^{7,8}$. One of its characteristic features is that it only occurs in relatively narrow band, approximately 150-300 m ATGL, riding on top of the inversion. Thus, it would only facilitate the rapid removal of pollutants from those plumes which intercept the LLJ, while emissions from very tall stacks mostly rise above this layer. Furthermore, the LLJ is limited to night periods lasting until early morning and will therefore not be as effective as air mass transport or large-scale washout. Since no suitable vertical wind profiles were available, the LLJ could not be considered in the case studies, but should be investigated as part of a regional experiment.

As far as synoptic systems are concerned, migrating anticyclones contribute most to the RC cases, especially during September and October, when the frontal activity is at its highest. During wintertime, the bud-off anti- 
cyclone produces an air mass movement, which represents a loop to the north of the source area (Figure 2 , left). During summertime, when the bud-off anticyclone migrates further east and to the south of the Highveld (due to the seasonal shift of the anticyclonic pressure belt), the air mass movement describes a loop to the east (Figure 2, right). During transport beyond the network area, most of the conversion of the primary gases can take place so that the return flow will then increase the $\mathrm{SO}_{4}{ }^{2-}$ concentrations over the network area rapidly, sometimes very suddenly from one day to the next. Other systems, producing a more random pattern of air mass movement, occur during summertime. They belong to the class of mesoscale circulation systems, like continental heat lows and mesoscale convective systems.

Based on more than 150 case studies $^{6}$, it was found that the most severe sulphate episodes at the surface were the result of air masses moving out of and re-entering the network area, occasionally even several times. The criterion to discern the sulphate reservoir re-entering the network was the rapid increase of the sulphate level over a large area. Another mechanism contributing to a rapid increase of the sulphate level is downmixing (DM) when peak values can be reached within less than 24 hours. High sulphate values were recorded at Verkykkop (300 m AGL) on days prior to rapid increases of sulphate levels at the surface. Downmixing of such sulphate-rich air from a postulated reservoir aloft could therefore have contributed to the increase of the surface levels. Downmixing on a more local scale has been found to occur over the Witwatersrand watershed during noctural periods ${ }^{9}$.

During some months the sulphate behaviour between the surface and the Verkykkop sampling site was either strongly negatively or strongly positively related. The pollutant reservoir aloft and downmixing could function as the coupling mechanism and produce peak events at the surface and on the escarpment. Some months, which show a high variability of the sulphate concentration at the surface or on the escarpment, could indicate that the episodes were fed by the postulated reservoir aloft and that recirculation could happen frequently.

High sulphate values on the escarpent (Verkkykop) and low values at the surface on the ETH and in the northern OFS could be explained by the re-entering of an elevated layer with high $\mathrm{SO}_{4}^{2-}$ concentrations into the network area while at the same time the surface is well ventilated. This was observed a few times. The cause of the inverse behaviour, with high sulphate values at the surface and low values on the escarpment, could be due to the downmixing of particulate-rich air over a certain area on the Highveld, while the particulate reservoir aloft might be above $300 \mathrm{~m} \mathrm{AGL}$ and it would therefore not intercept the Verkykkop site. Vertical profiles of particulates obtained by means of a radio-controlled sampling platform in various parts of the Highveld confirm not only the existence of such a particulate reservoir on most days, but also show that the maximum concentrations vary in height between 200 and $500 \mathrm{~m} \mathrm{AGL}^{4}$.
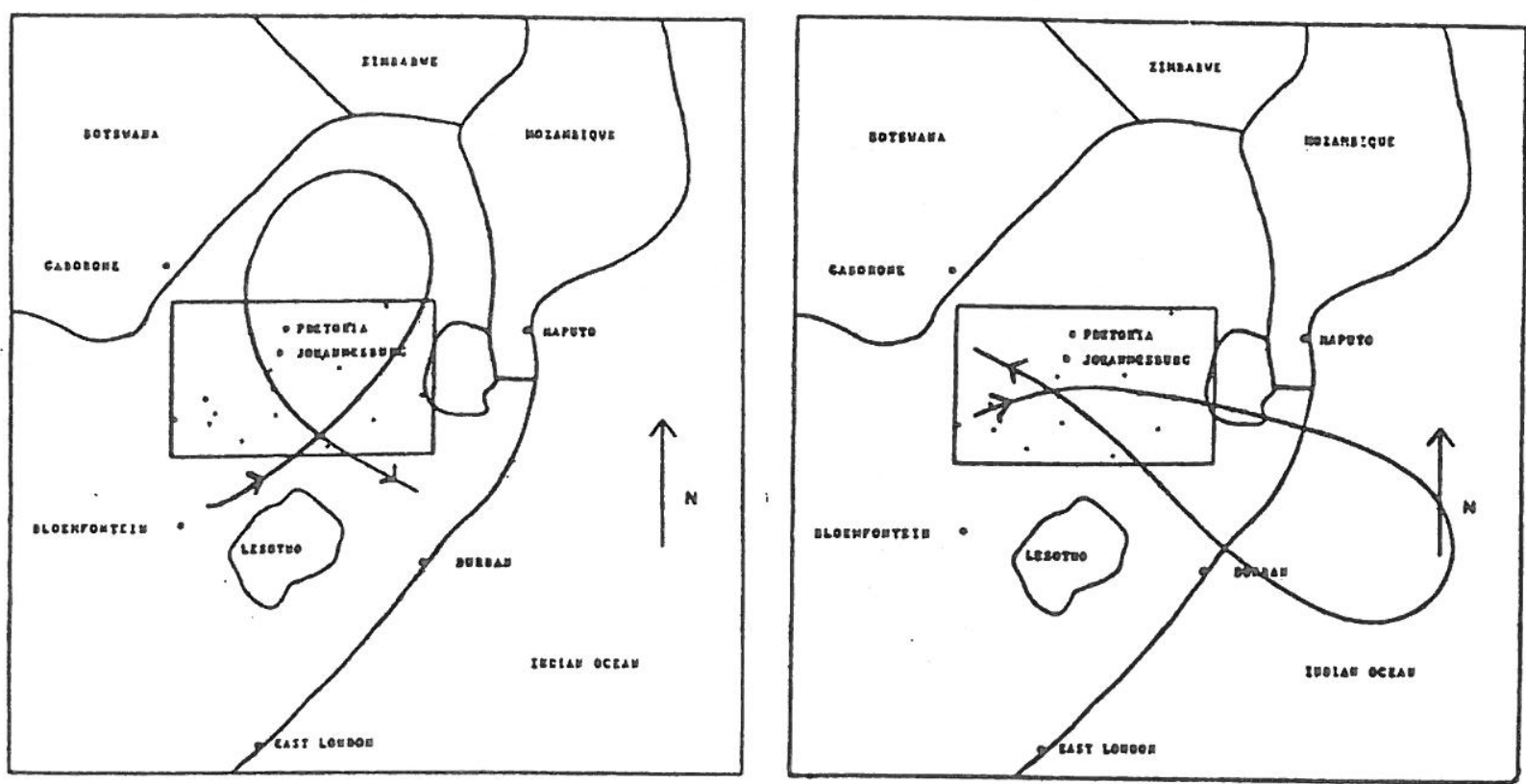

Figure 2. Characteristic windpaths during budding events from May to July (left) and from August to April (right). 


\section{SELECTED CASE STUDIES OF THE SULPHATE BEHAVIOUR ON THE HIGHVELD}

\section{Surface Episodes}

From a wealth of case studies investigated ${ }^{6}$, a few typical situations containing most of the significant features observed have been selected for this discussion.

A typical winter synoptic situation at the end of July and beginning of August 1987 was characterised by the Indian Ocean anticyclone dominating the pressure distribution over the Highveld. Wind speeds remained low within the mixing layer and the wind path at Elandsfontein showed a high variability of the wind direction for that period, indicating stagnation and possible accumulation of pollutants over the Highveld (Figure 3). Although the Elandsfontein hill is only elevated about $150 \mathrm{~m}$ above the surrounding terrain and thus not at plume level, wind records from this site were considered as the most suitable ones for the study because they were obtained within the source area and continuously available for hourly intervals. Furthermore, they were quite consistent with observations at Irene for the 775 and $700 \mathrm{hPa}$ levels ${ }^{5}$. In order to demonstrate the sensitivity of the wind field and how, in turn, the ground-level sulphate distribution over the Highveld responded to the changes of the pressure pattern associated with the following passage of a low pressure system (Figure 4), a sequence of $\mathrm{SO}_{4}{ }^{2-}$ maps was compiled in Figure 5 to 7. The rectangle in these figures corresponds with the sulphate measuring network. The actual sulphate distribution is known only within the network area, but in order to show the movement of the sulphate reservoir due to the changing wind field, the sulphate distribution was graphically extrapolated over a range beyond the measurement network based on daily plots of the isopleths within the network. After having consulted the anemometer recordings on the Highveld (four to five locations) and the synoptic maps for air mass transport, the most reasonable way to close the isolines was chosen. The area enclosed by $1 \mu \mathrm{g} \cdot \mathrm{m}^{-3} \mathrm{SO}_{4}^{2 \cdot}$ isopleth could be defined as the sulphate reservoir.

The first synoptic event reflected by the change of the sulphate distribution at the surface was the passage of a low, southeast of the subcontinent, during 2 to 5 August 1987 and the migration of a bud-off anticyclone from the Atlantic to the Indian Ocean (Figure 4). As a consequence of the passage of the trough, cooler and moister air was advected over the Highveld and the wind speeds also increased during 4 and 5 August 198. As the cyclone approached, the air mass moved northeastwards with the southwesterly flow and the sulphate reservoir was shifted likewise (Figures 3,5 and 6). The bud-off anticyclone reversed the air flow from southwesterly to northeasterly during 5 August 1987. After the cyclone had passed the sulphate reservoir began to move back into the network area (Figure 3). The wind finally turned north when the bud-off anticyclone merged with the Indian Ocean anticyclone and the sulphate reservoir continued to shift in a southerly direction, while increasing the sulphate level in the centre of the network area (Figures 3 and 7). The mean sulphate concentration over the whole area peaked on 7 August 1987 after the sulphate reservoir had moved back into the network area (Figure 8).

The anticyclonic influence caused strong subsidence over the Highveld (Figure 9), which is a very common phenomenon, especially during winter, occurring on up to $79 \%$ of winter days ${ }^{10}$. At the same time, a northerly flow over the area continued to shift the sulphate reservoir further southwards (Figure 3). The wind path recorded at Elandsfontein and Kendal stack, from 7 to 12 August 1987, measured an air mass movement of 1300 to 2000 $\mathrm{km}$, which demonstrates the transport capability of the flow. The pressure gradient, and subsequently the wind speed, increased when a trough approached the subcontinent during 10 August 1987 (Figure 10). Dry air flowed into the southwestern portion of the research area (Figure 11). As The cyclone passed by south of the subcontinent, the wind direction veered to the northwest and then backed to southerly at Elandsfontein (12 August 1987, Figure 3). Due to the intensifying ventilation, the total sulphate concentration dropped to $1,2 \mu \mathrm{g} \cdot \mathrm{m}^{-3} / 24 \mathrm{~h}$ on 12 August 1987 (Figure 8).

As a result of the northwesterly off-shore flow, a coastal low was established over the southeastern coastline. Its presence was linked with subsidence warming over the Durban area and the creation of a low-level elevated inversion (Figure 12). The upper arrow in Figure 12, pointing to the right, indicates the warming at the $900 \mathrm{hPa}$ level from 8 to 12 August 1987 and the lower arrow, pointing to the left, the cooling from 11 to 12 August 1988 below $900 \mathrm{hPa}$, which resulted in a low-level elevated inversion. The cooling of the lowest $100 \mathrm{hPa}$ before the passage of the front could be attributed to the coastal low which advected maritime air within its southern portion while migrating northwards along the coast. The cold air mass following behind the cold front was much deeper $(1000-600 \mathrm{hPa})$ than the comparatively shallow layer of cold air advected by the coastal low (Figure 13). Under the given circulation pattern, it is highly likely that air containing emissions from the Highveld was transported to the coastal areas to become trapped under the lowlevel elevated inversion created there. Due to the subsidence warming on the way down to the coast, the lower atmosphere containing the pollutants was already stabilised when it arrived over the coastal lowlands.

During 12 and 13 August 1987, a bud-off anticyclone migrated eastwards, trailing behind the trough (Figure 14). The flow reversed when the Atlantic anticyclone began to extend eastwards into the ETH area behind the cold front, during the second half of 12 August 1987 (Figure 3). A day later, the $\mathrm{SO}_{4 t}{ }^{2-}$ values began to increase at Verkykkop, after the wind direction had already turned 


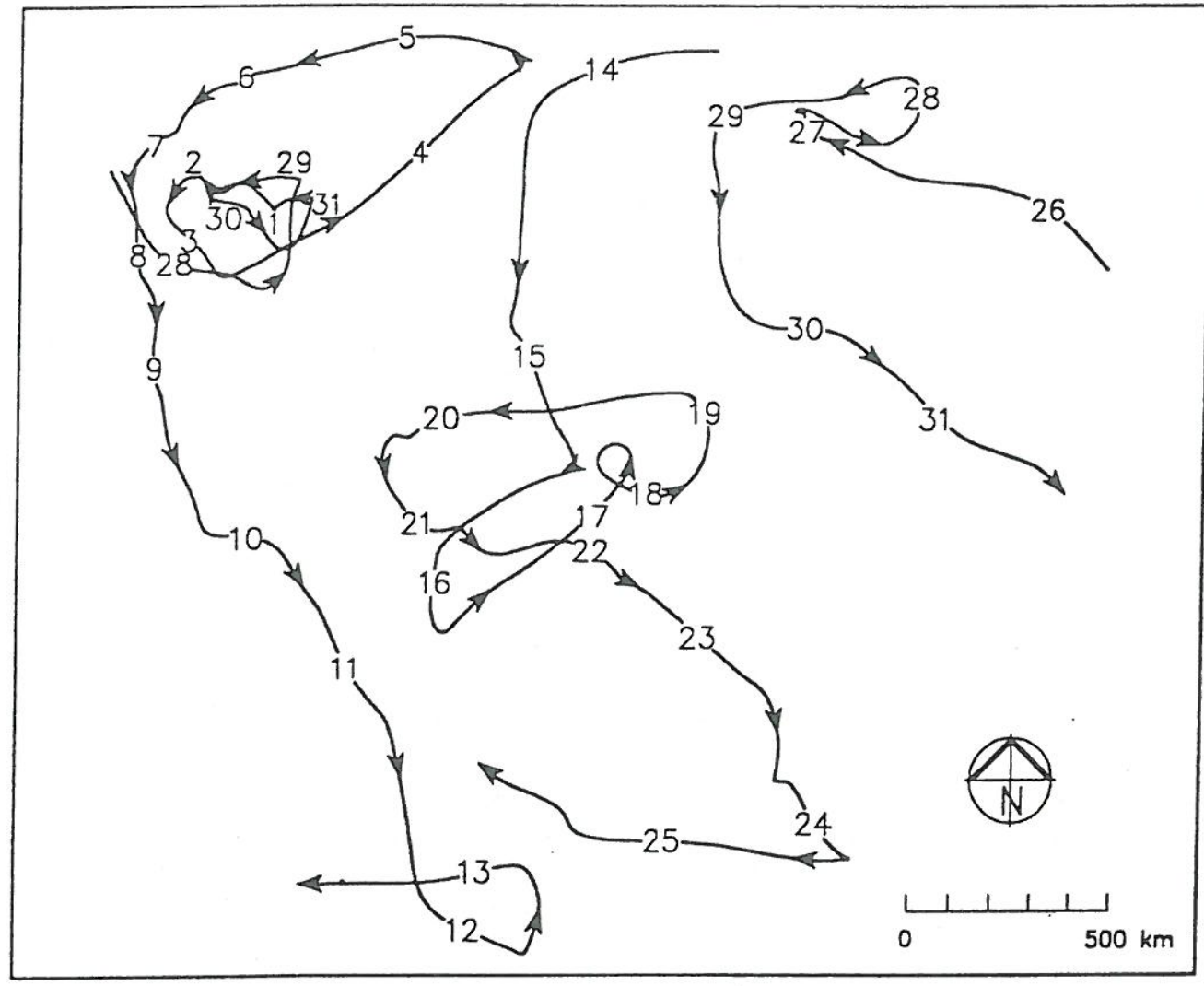

Figure 3. The wind path at Elandsfontein from 28 July 1987 (beginning at upper left corner) to 31 August 1987 . The plot is based on the hourly mean wind speed and direction

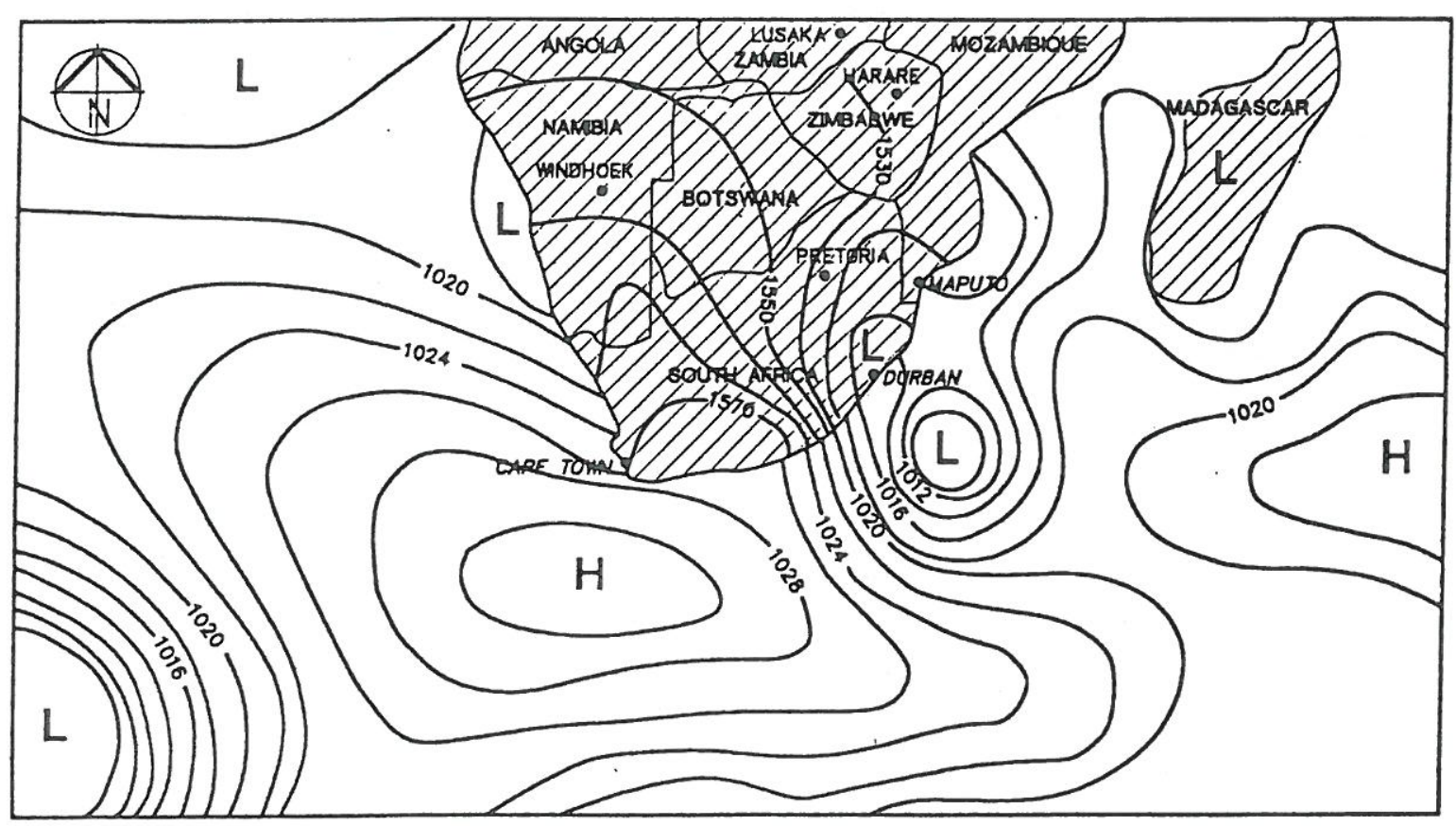

Figure 4. Synoptic map for 4 August 1987, 14:00 SAST. 
east on the TH (Figure 8). The actual peak occurred on 14 August $1987\left(56,8 \mu \mathrm{g} \cdot \mathrm{m}^{-3} / 24 \mathrm{~h}\right)$, when the wind turned another $90^{\circ}$ from east to north. With a northernly component in the flow, additional direct advection of particulates from the source area was possible. A cold moist air mass swept across the Highveld, on the same day, in a layer between the surface and $700 \mathrm{hPa}$ (Figure 15). The vertical stratification of the air mass, which arrived on the Highveld, was another feature which betrayed its origin when peak $\mathrm{SO}_{4}^{2-}$ values occurred on Verkykkop. The low-level elevated inversion over Irene on 14 and 15 August 1987 (Figure 16) very much resembles the inversion over Durban on 12 August 1987 (Figure 12). The inversion over Irene was at about $800 \mathrm{hPa}$, which also corresponds to the elevation of the Verkykkop station.

The absolute minimum concentration of sulphate at ground level, during the month, occurred on 17 August 1987 and can be related to the advection of very dry continental air into the network area (Figure 8).

\section{Episodes at Verkykkop}

Most of the peak episodes at Verkykkop are decoupled from episodes at the surface and occur as peak values far above the average. Thirteen such cases have been described in detail ${ }^{6}$. All episodes at Verkykkop were preceded by a period of fine days when an accumulation of particulates $\left(\mathrm{SO}_{4}{ }^{2}\right)$ at the surface could be observed. The reservoir of particulates was never completely removed or destroyed before an episode. During a period with accumulation of particulates at the surface, the Indian Ocean anticyclone extended its axis over the Highveld. During wintertime, the Atlantic Ocean anticyclone and the Indiean Ocean anticyclone can form an anticyclone bridge across the subcontinent.

The density of the isobars and consequently the pressure gradient tended to be low. Therefore the wind paths at the various anemometer sites were short and highly variable in direction. The anticyclone was usually warm and deep so that the wind speeds were low throughout most of the boundary layer. Temperatures increased and moisture remained at the initial level or increased slightly but never dropped significantly. Occasionally a strong subsidence inversion marked the upper boundary of the mixing layer. The $\mathrm{SO}_{4}{ }^{2-}$ values increased at the surface stations and in cases without significant horizontal transport, the area with the highest concentrations could be found at Slangheuwel and Heilbron.

The air mass containing high concentrations of particulates is subsequently subjected to various physical processes in the atmosphere. Two meteorological mechanisms are of decisive importance for the creation of the peak episodes at Verkykkop. The first one might be called recirculation, which means transport of the pollutants out of their source area and back again after the flow had reversed. The other one is responsible for the modification of the stratification of the air mass containing the pollutants with a resultant formation of a pollutant reservoir. A very stable environment must be created and kept effective, if the pollutants are to remain largely undiluted. Details of such case studies have already been published ${ }^{11}$.

\section{CONCLUSIONS}

The behavioral patterns of the five particulate species ( $\mathrm{F}$, $\mathrm{Cl}^{-}, \mathrm{PO}_{4}{ }^{3}, \mathrm{NO}_{3}{ }^{-}$and $\mathrm{SO}_{4}{ }^{2-} ; 24$-hour mean values) measured on the South African Highveld during a five-year period, have been discussed. It has been tried, for the first time, to relate the variation in concentration of these anions to variations of physical parameters of the atmosphere. The behaviour of the particulates on the South African Highveld differs in many respects from what is known about particulates in the northern hemisphere. The unique combination of industrial settlements on the plateau of the Southern African continent, with its subtropical climate, may account for the phenomena solely recorded there.

Summarising the meteorological conditions leading to high and low pollution episodes, one can state that the sulphate behaviour at the surface of the South African Highveld appears to be quite comparable with overseas observations in respect of meteorology. Photochemistry forms an integral part of atmospheric processes taking place on and around the South African Highveld, which climatologically has to be counted among the subtropical regions of the globe. The two crucial factors defining the sulphate level, which could be reached on the Highveld, are the air mass type residing over the area and the pressure system, governing the intensity and direction of the air mass flow. Generally warm moist air, either of tropical or subtropical origin, together with a weak pressure gradient over the area provides the best possible environment for accumulation, photochemical activity and consequently for high sulphate levels. On the other hand, ventilation or advection of dry continental air, as well as washout events, can reduce the sulphate levels effectively. A few typical weather patterns exist which can be linked to these effects on the sulphate levels.

With respect to peak events at Verkykkop ${ }^{11}$, the presence of a maritime-type air mass is a prerequisite, since lowlevel elevated inversions are then well developed. The peak concentrations are then caused either by a budding event or direct advection. The occurrence of these meteorological phenomena follows a double-wave seasonal pattern with a pronounced spring-time and a minor autumn frequency maximum.

To assess the efficiency of the ventilation on the Highveld with the existing size of the network is a difficult task. The network area would have to be enlarged up to the radius that a recirculation event could possibly reach. If a ventilation event was able to reduce the sulphate concentration within this enlarged area, one could assume that the pollutants have left the network irreversibly. 


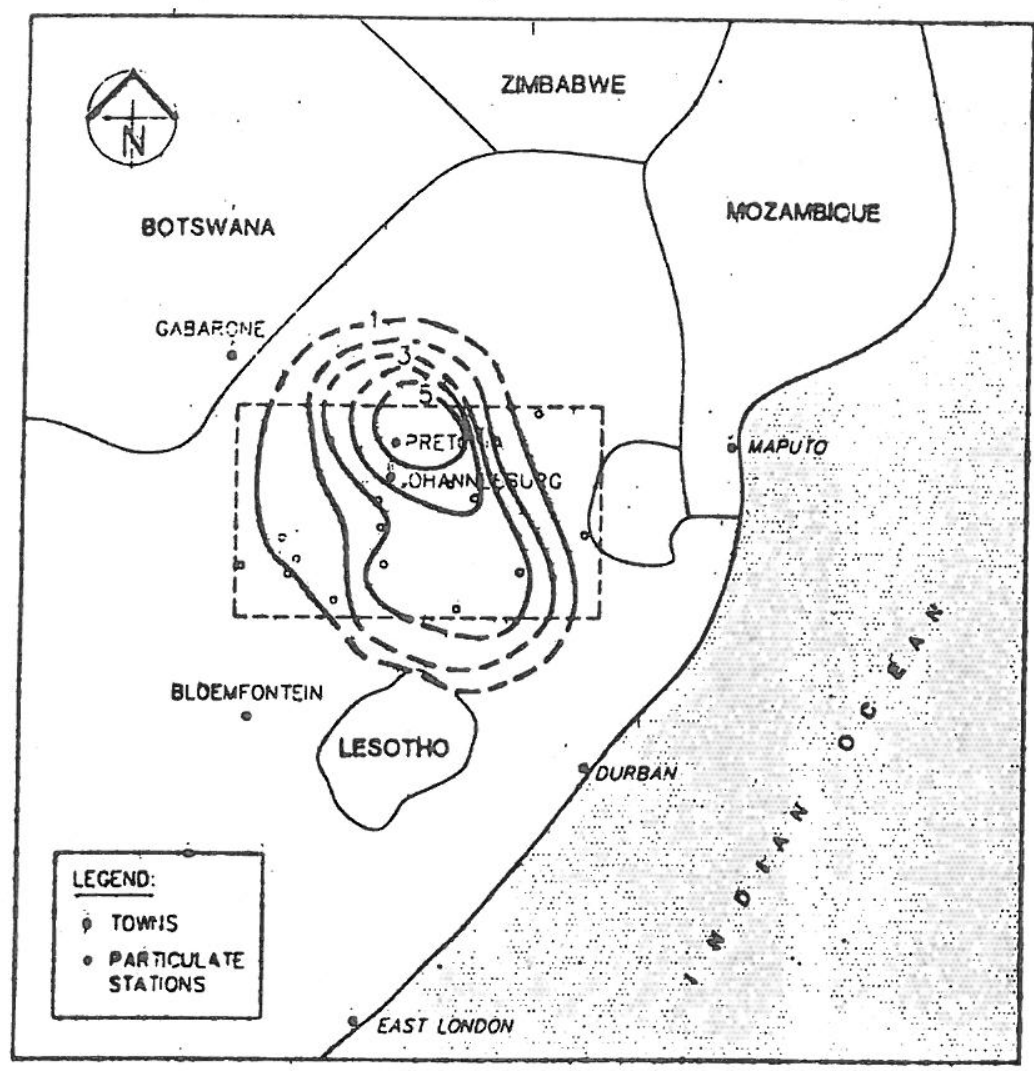

Figure 5. $\mathrm{SO}_{4}{ }^{2-}$ distribution over the South African Highveld on 2 August 1987 extrapolated beyond the network area (dashed lines) Units in $\mu \mathrm{g} \cdot \mathrm{m}^{-3} / 24 \mathrm{~h}$.

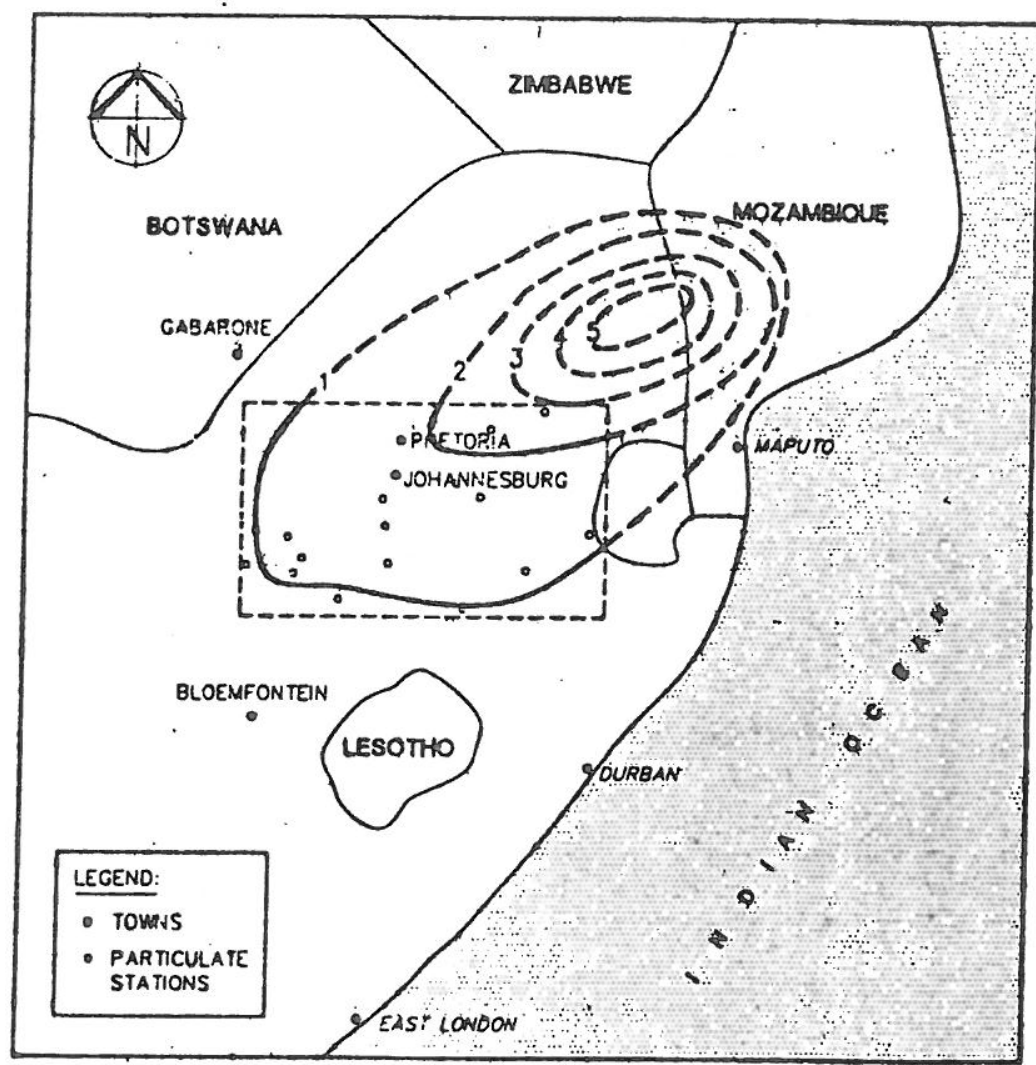

Figure 6. $\mathrm{SO}_{4}{ }^{2-}$ distribution over the South African Highveld on 4 August 1987 extrapolated beyond the network area (dashed lines). Units in $\mu \mathrm{g} \cdot \mathrm{m}^{-3} / 24 \mathrm{~h}$. 


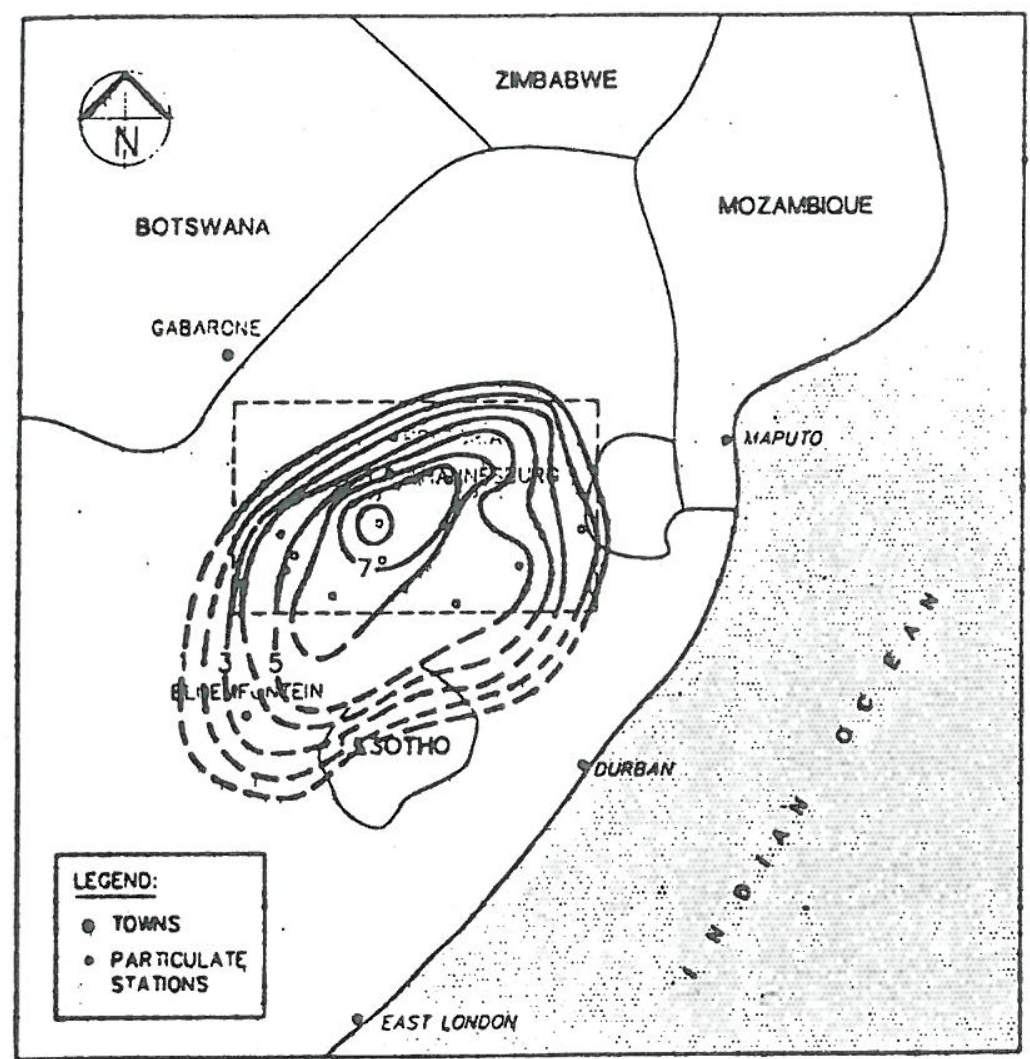

Figure 7. $\mathrm{SO}_{4}^{2-}$ distribution over the South African Highveld on 7 August 1987 extrapolated beyond the network area (dashed lines). Units in $\mu \mathrm{g} \cdot \mathrm{m}^{-3} / 24 \mathrm{~h}$.

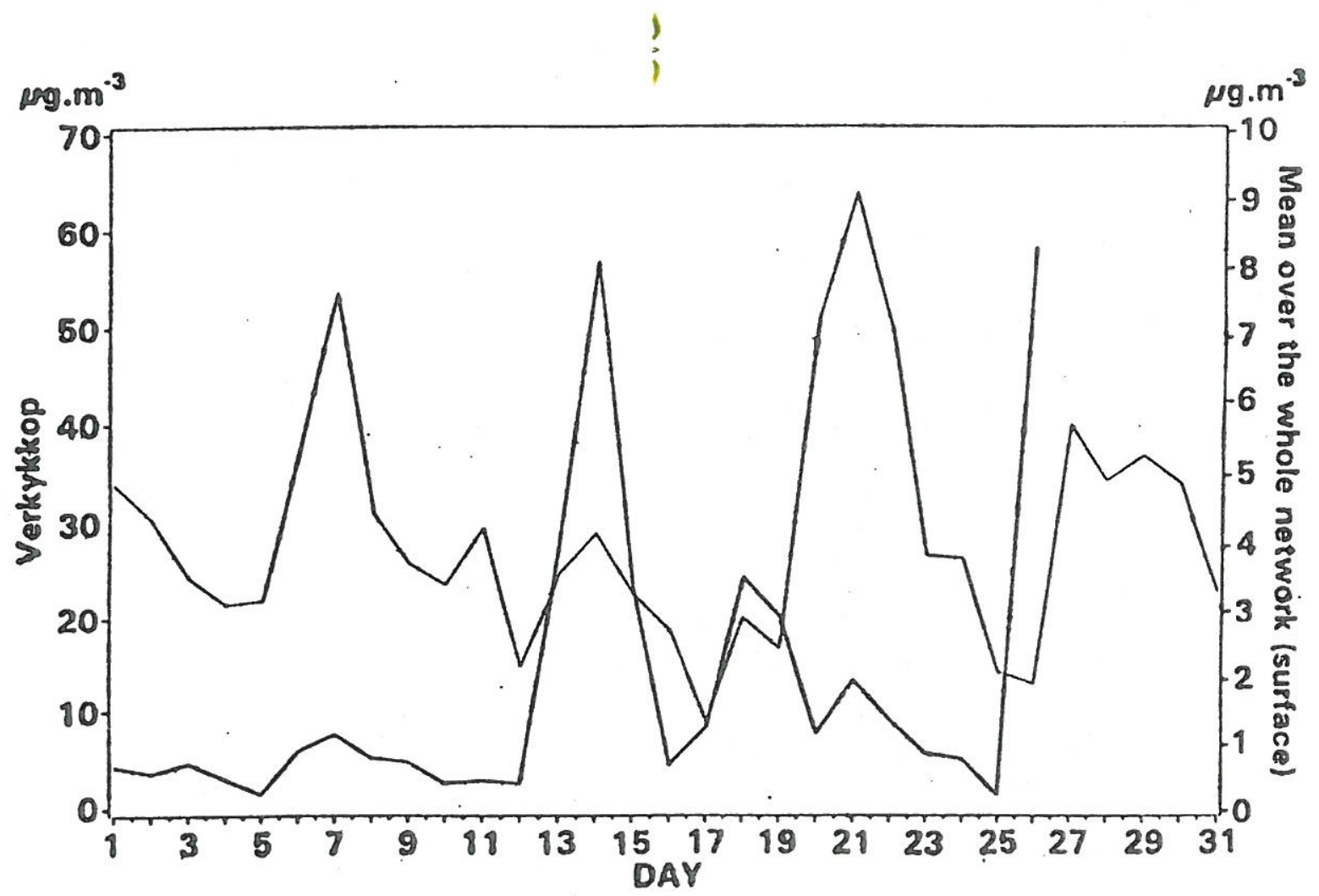

Figure 8. Time series of sulphate concentrations at the surface (thin line, $\mathrm{SO}_{4}{ }^{2-}$ mean concentration of all stations available on a day, exaggerated seven times) and at Verkykkop (bold line, $\mathrm{SO}_{4}{ }^{2}$ ) in $\mu \mathrm{g} \cdot \mathrm{m}^{-3} / 24 \mathrm{~h}$ during August 1987 


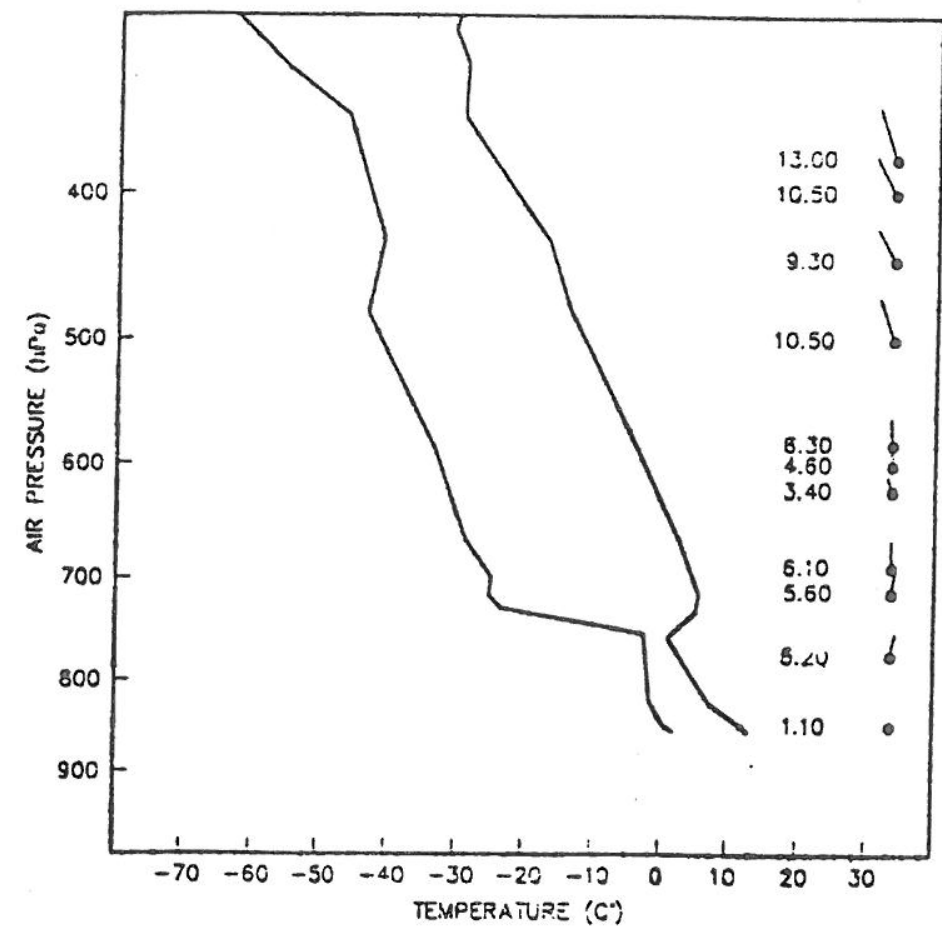

Figure 9. Radiosonde ascent from Irene, 8 August 1987, 14:00 SAST. Dewpoint (left line), temperature (right line) and wind speed (m.s. $\left.{ }^{-1}\right)$ and direction (right hand side).

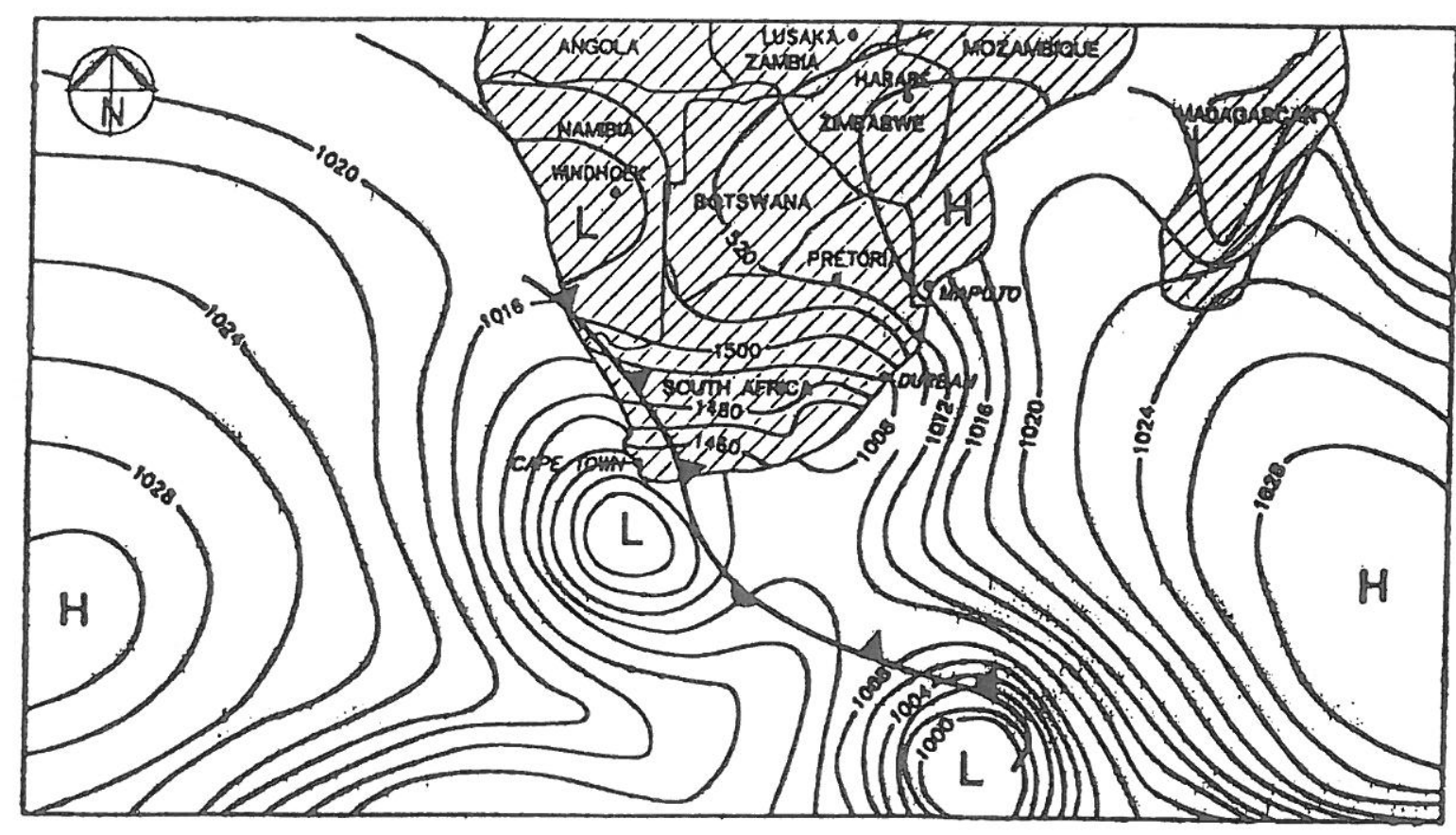

Figure 10. Synoptic map for 11 August 1987, 14:00 SAST 


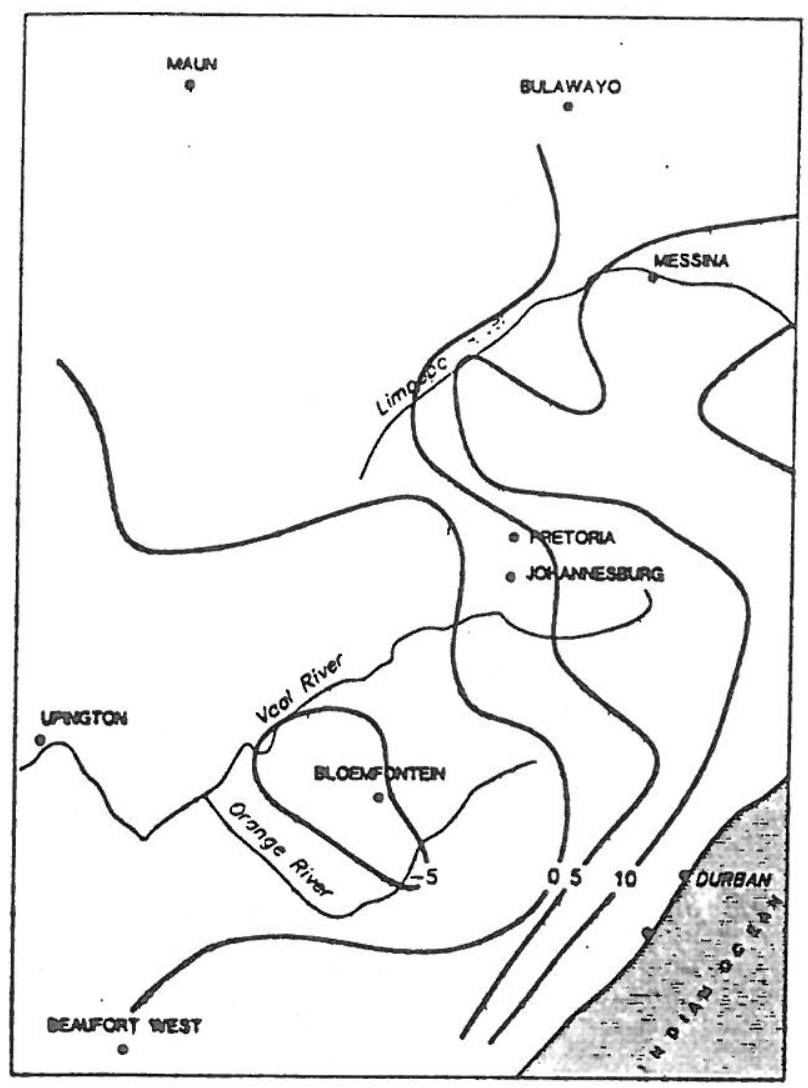

Figure 11. Dewpoint temperature $\left({ }^{\circ} \mathrm{C}\right)$ distribution over part of Southern Africa on 13 August 1987, 14:00 SAST

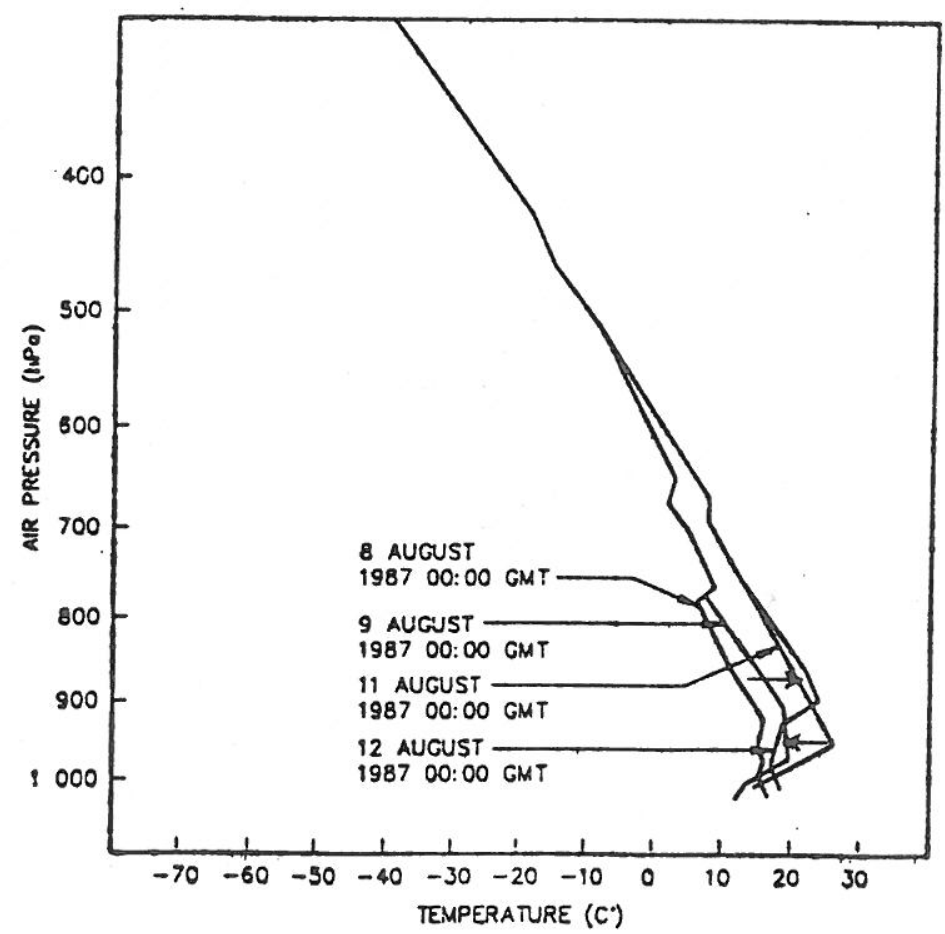

Figure 12. The changing temperature profile over Durban from 8 to 12 August 1987. The upper isolated arrow pointing right indicates the warming from 8 to 11 August 1987 and the lower arrow pointing left the cooling from 11 to 12 August 1987. 


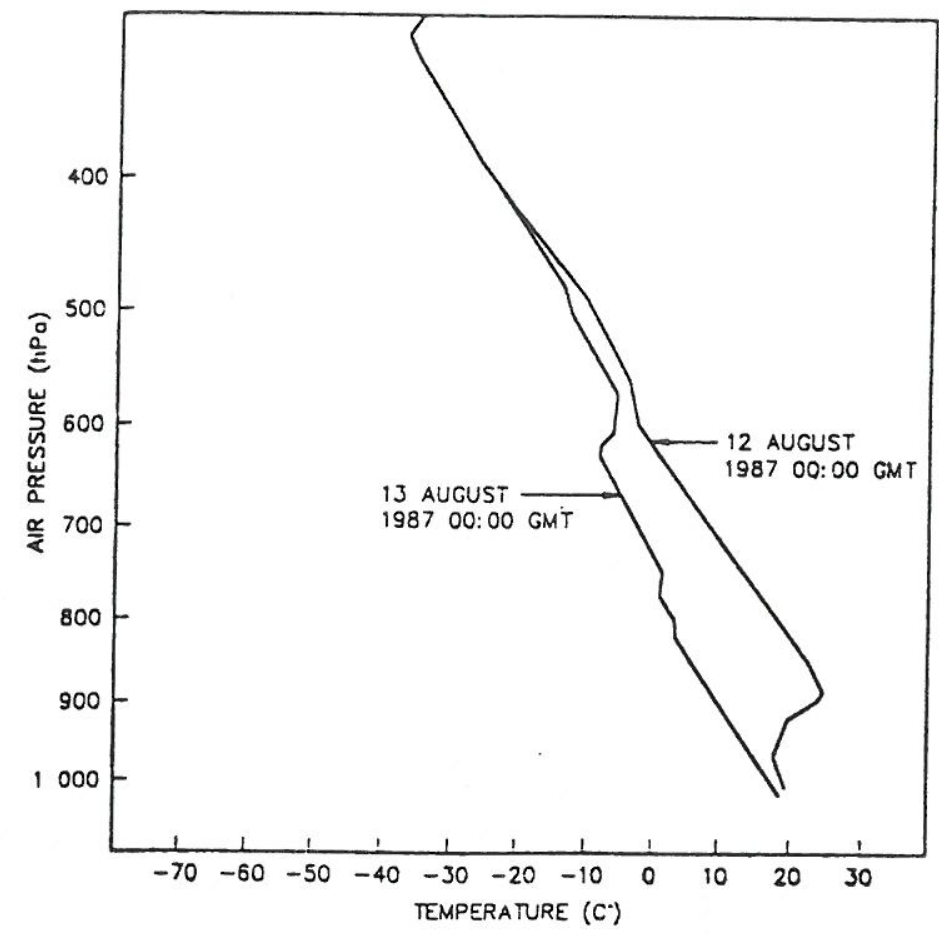

Figure 13. A major cooling of the lower troposphere is indicated by the temperature profiles of 12 and 13 August 1987 over Durban.

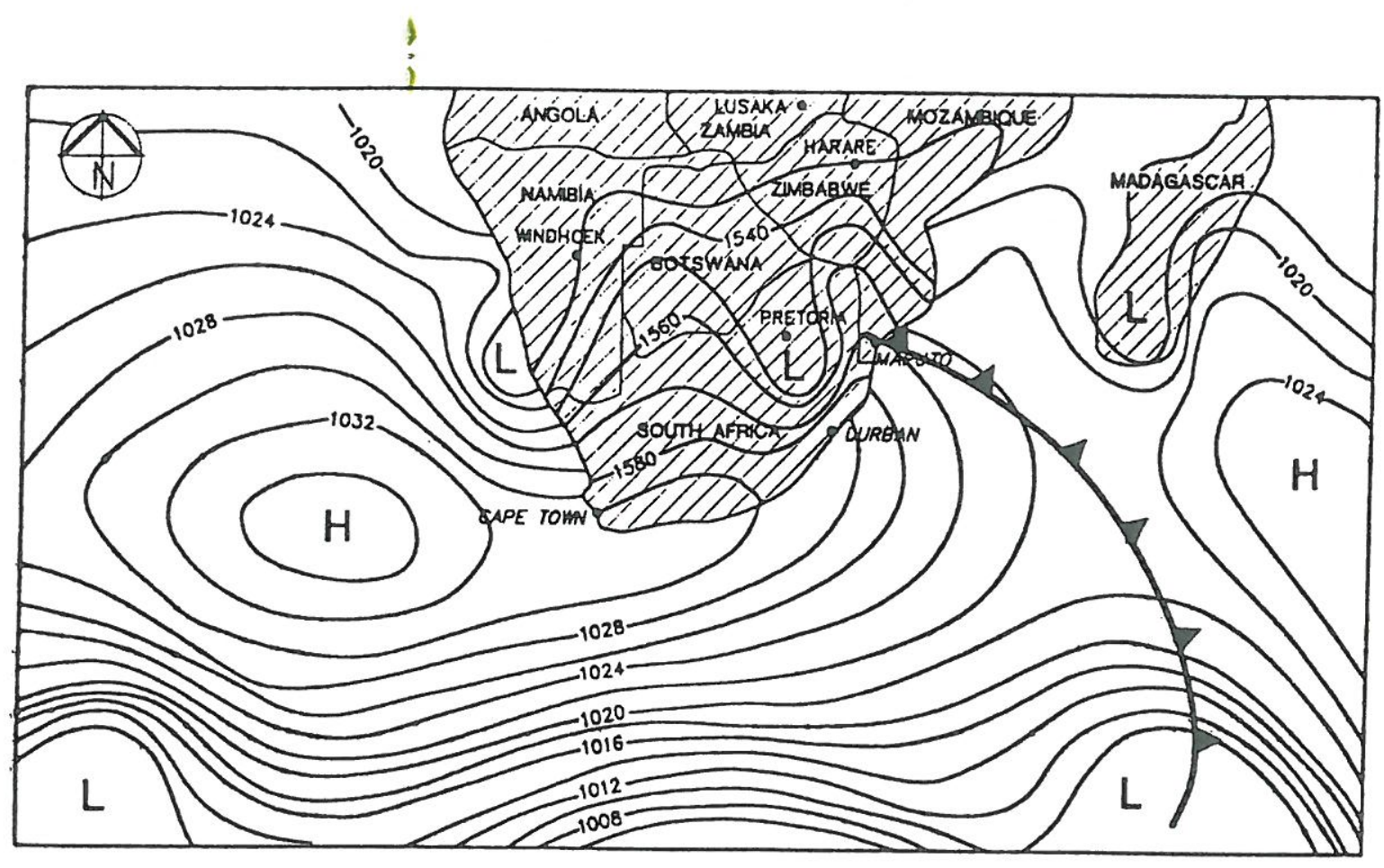

Figure 14. Synoptic map for 13 August 1987, 14:00 SAST. 


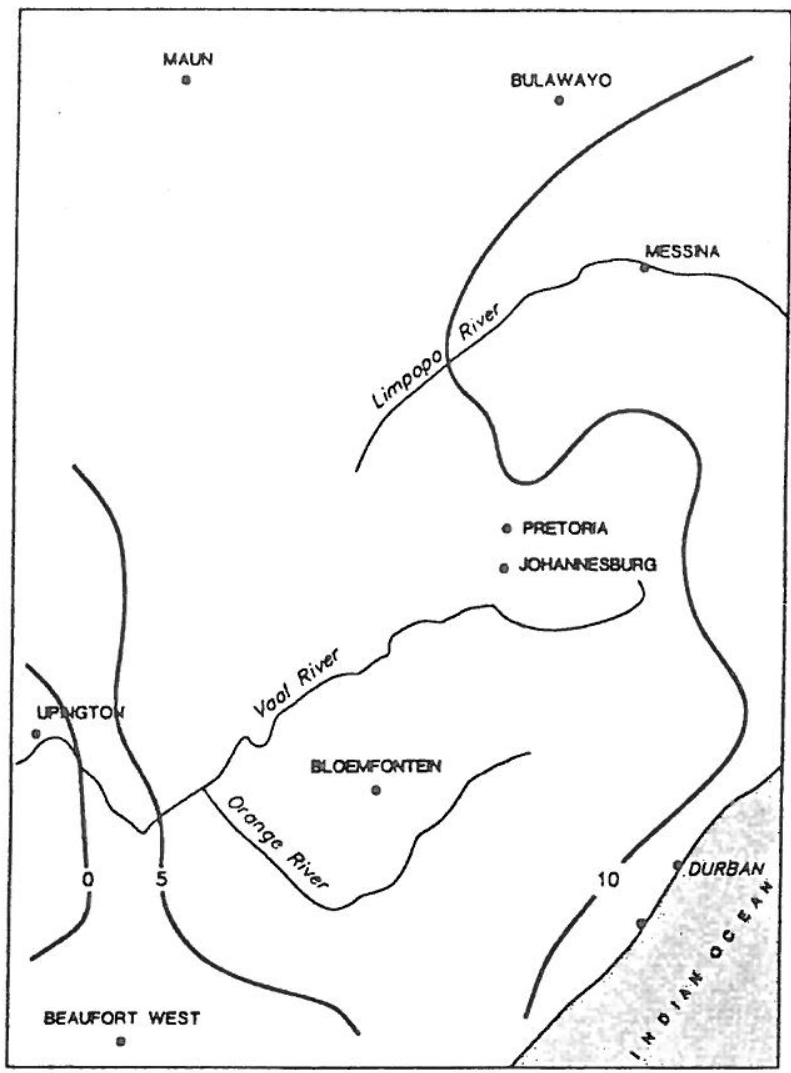

Figure 15. Dewpoint temperature $\left({ }^{\circ} \mathrm{C}\right)$ distribution over part of Southern Africa on 14 August 1987, 14:00 SAST.

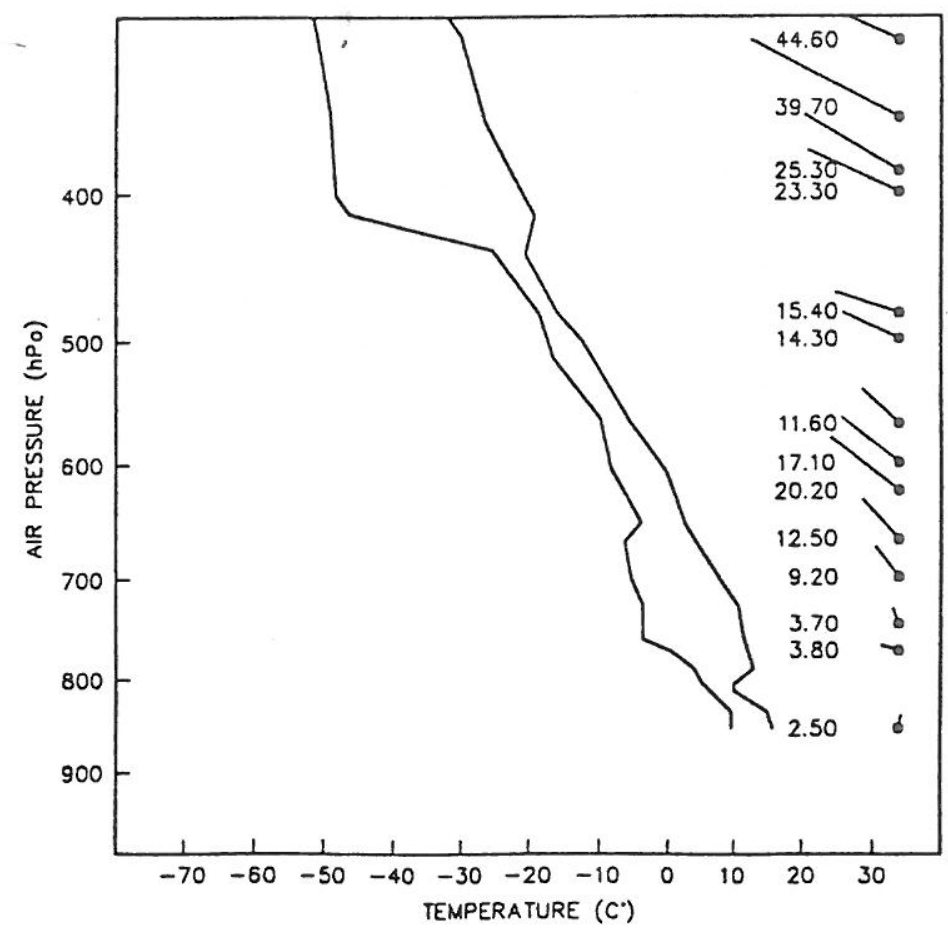

Figure 16. Radiosonde ascent from Irene, 15 August 1987, 14:00 SAST. Dewpoint (left line), temperature (right line) and wind speed $\left(\mathrm{m} . \mathrm{s}^{-1}\right)$ and direction (right hand side).

In order to assess the total $\mathrm{SO}_{4}^{2-}$ mass, which can be accumulated during an episode, the extrapolated $\mathrm{SO}_{4}{ }^{2}$ distribution for 7 August 1987 was chosen as representing a typical example (Figure 7). Integrating the total $\mathrm{SO}_{4}^{2-}$ mass over a volume which is equal to the radius of the 1 $\mu \mathrm{g} \cdot \mathrm{m}^{-3}$ isopleth (about $250 \mathrm{~km}$ ) multiplied by the level of 
the subsidence inversion over the area on that date (about $1200 \mathrm{~m}$ AGL over Irene) and a mean concentration of 4 $\mu \mathrm{g} . \mathrm{m}^{-3}$ gives about $94000 \mathrm{t} \mathrm{SO}_{4}{ }^{2-}$. Assuming a total input of $3000 \mathrm{t}$ of $\mathrm{SO}_{2}$ a day over the total area results (immediate conversion assumed) in a daily addition of $4500 \mathrm{t}$ of $\mathrm{SO}_{4}{ }_{4}^{2-}$. The total amount of $\mathrm{SO}_{4}{ }^{2-}$ observed on 7 August 1987 would only have been reached after about 21 days of accumulation, based on the above calculation. This type of rough assessment can be criticised as being too simple, but it at least shows that to accumulate such quantities of $\mathrm{SO}_{4}{ }^{2-}$ during an episode requires a time span of considerably more than a few days. It is therefore rather unlikely that local accumulation of pollutants in quasistationary air masses present over the Highveld area can produce the observed quantity of $\mathrm{SO}_{4}{ }^{2-}$ during an episode preceded by an efficient ventilation event.

As it is now apparent that local conversion and accumulation cannot contribute significantly to an episode within a time period of a few days, rapid increases of the $\mathrm{SO}_{4}{ }^{2}$ concentration at the surface within less than a week have to be attributed mainly to mesoscale recirculation. In case a ventilation event empties the reservoir completely, it should take weeks to be refilled. The size of the reservoir remains a crucial factor, but is difficult to assess; a much smaller volume of air with a high $\mathrm{SO}_{4}^{2-}$ concentration could be created quickly, but never these volumes which are observed during a major episode, covering most of the network area. The surface $\mathrm{SO}_{4}{ }^{2-}$ distribution during peak episodes suggests that the actual reservoir reaches far beyond the boundaries of the network. Also, a major part of the conversion of primary pollutants might take place outside the network area. If an air mass with high $\mathrm{SO}_{2}$ concentration leaves the Highveld, conversion will take place during transport before the same air might be recirculated with a higher sulphate concentration than before, assuming that no dry or wet deposition took place. A return flow of particulate-enriched air into the network is not always easily detected, except when the difference in $\mathrm{SO}_{4}{ }^{2-}$ concentration between the advected air and the residing air inside the network is large enough to make an inflow noticeable. Quasistationary conditions make it especially difficult to infer a wind field from one upper air station and a few anemometer sites over an area of 270 by $500 \mathrm{~km}$. The return flow of particulate-rich air might happen very subtly and mimic a local conversion of $\mathrm{SO}_{2}$.

The field of investigation related to the particulate problem is much wider than addressed by this study. The most limiting factor represents the lack of data at the beginning and the end of the cycle emissions-transporttransformation-deposition. This is currently being addressed in a joint Eskom/CSIR project, which investigates the diurnal variation of particulates as well as conversion and possible recirculation processes ${ }^{12}$. In order to complete the picture of the relationship between air pollution and atmospheric physics over the South African Highveld, a study of the precursors of the particulates and deposition also need to be included and is currently being undertaken. Such a procedure, coupled with ongoing impact studies, for example on the escarpment, will finally enable a realistic assessment of the pollutant budget on the Highveld, which is essential to determine whether or not the ecosystem could be affected by air pollution.

\section{ACKNOWLEDGEMENTS}

This research project is based on data which had been collected as part of an investigation into air pollution levels in the Eastern Transvaal Highveld and the northern Orange Free State, which was initiated by the then Office of the Prime Minister: Physical Planning Branch (now Department of Development Planning). Since 1984, the project had been financially supported by the Department of National Health and Population Development through the Foundation for Research Development with contributions from other Government Departments and the CSIR. The final analysis and synthesis of results was completed while the authors were still affiliated to Ematek (CSIR) and financed by Eskom Engineering Investigations under contract "PACAMS".

The South African Weather Bureau in Pretoria, especially Mr J A Koch, is acknowledged for providing the required meteorological data. The contributions of Ematek's technical staff for obtaining the measurements and analysing the samples are gratefully acknowledged. A special word of thanks is also due to Mrs S G Good for professionally typing the manuscript.

Permission from Eskom, Technology Research and Investigations and CSIR, Ematek to present this paper is acknowledged.

\section{REFERENCES}

1. Wells R B, Snyman G M, Held G and Dos Santos A (1987). Air pollution in the Eastern Transvaal Highveld. CSIR Report ATMOS/87/23, Pretoria, 1-147.

2. Held G, Snyman G M, Wells R B, Danford I R, Hong $Y$ and Scheifinger $H$ (1990). Conditions causing high concentrations of sulphate and nitrate in an elevated layer over the South African Highveld. Proceedings of 83rd Annual Conference of the Air \& Waste Management Association, Pittsburgh, USA, Paper No. 90-100.6, 1-13.

3. Snyman G M and Held G (1989). Air pollution and meteorological studies in the southeastern Transvaal Highveld. Annual Progress Report to FRD, CSIR, Pretoria, 1-55.

4. Snyman G M, Held G and Brassel K M (1990). Vertical profiles of particulates on the South African Highveld. Proceedings of the 1st IUAPPA Regional Conference on Air Pollution: Towards the $21 s t$ Century. Pretoria, 24 - 26 October 1990, Volume I, No. 52, 1-17. 
5. Scheifinger H, Held G and Snyman G M (1991) Study of possible accumulation of pollutants in the atmosphere of the Highveld. A Report to Eskom Engineering Investigations, CSIR Report EMA-C 91173, Pretoria, 1-79.

6. Scheifinger H (1991). Particulate climatology of the South African Highveld. Unpublished $\mathrm{PhD}$ Thesis. Submitted to the University of Vienna, Austria.

7. Held G, Danford I R, Hong Y, Tosen G R and Preece A R (1990). The life cycle of the low-level wind maximum in the eastern Transvaal Highveld (a cross-sectional study). A Report to CSIR Executive and Eskom, Engineering Investigations. CSIR Report EMA-C90146, Pretoria, 1-50.

8. Tosen G R, Held G, Hong Y, Danford I R and preece A R (1990). The life cycle of the low-level wind maximum in the eastern Transvaal Highveld. Proceedings of the 1st IUAPPA Regional Conference on Air Pollution: Towards the 21st Century. Pretoria, 24-26 October 1990, Volume I, No. 38, 1-14.
9. Langenberg H M (1991). Preliminary findings on the "watershed air sink" of the Witwatersrand. Proceedings of the Symposium on Air Pollution and the Environment, Durban, 14-15 November 1991, Vol. 2, Paper No. 12, 1-13.

10. Preston-Whyte R A and Tyson P D (1988). The atmosphere and weather of southem Africa. Oxford University Press, Cape Town.

11. Scheifinger H (1992). Air mass movement and sulphate concentrations on the South African Highveld during August 1987. SA J Sci, 88, 391398.

12. Snymand G M, Held G and Taljaard J (1992). Comparative study of pollutants in the Eastern Transvaal (July 1991 - December 1991). Second interim report to Eskom T-R-I, CSIR Report EMA-C 91174B, Pretoria. 